DOI: http://dx.doi.org/10.12660/gvcasosv5n1c2

\title{
CASA DE BANHO E O DESAFIO DA RESPONSABILIDADE SOCIAL EM MICRO E PEQUENAS EMPRESAS
}

\section{Casa de Banho and the challenge of social responsibility in micro and small enterprises}

FERNANDO do Amaral Nogueira - fernando.nogueira @ fgv.br Escola de Administração de Empresas de São Paulo da Fundação Getulio Vargas - São Paulo, SP, Brasil

Cristina de Miranda Costa - kika.cristinacosta@ gmail.com

Escola de Administração de Empresas de São Paulo da Fundação Getulio Vargas - São Paulo, SP, Brasil

Submissão: 15/06/2014 | Aprovação: 23/04/2015

\section{Resumo}

Os microempresários Patrícia e Fernando precisam decidir se dão sequência ao incipiente programa de responsabilidade social de sua empresa.

O caso ilustra os processos de gestão típicos de uma microempresa e tem como principal objetivo possibilitar a discussão das características e desafios da implementação de programas de responsabilidade social em empresas desse porte.

Palavras-chave: Empreendedorismo, Micro e pequena empresa, Responsabilidade social, Gestão de empresas, Projetos sociais.

\begin{abstract}
Micro-businesspeople, Patrícia and Fernando, need to decide if they are going to continue with their company's incipient social responsibility program.

The case illustrates the typical management processes of a micro-enterprise and its main objective is to enable discussion of the implementation characteristics of social responsibility programs in companies of this size.
\end{abstract}

Keywords: Entrepreneurship, Micro and Small Enterprises, Social Responsibility, Business Management, Social Projects

"Nenhuma empresa é maior que as pessoas que a constituem"

Patrícia Helena Sturion e Cruz

Em poucas semanas, os microempreendedores Patrícia Helena Sturion e Cruz e Fernando Vale e Cruz precisam decidir se lançam a segunda turma de seu programa de aprendizes, em que contratam jovens de 16 a 18 anos em situação de risco social para se dedicar à preparação das embalagens dos perfumes e produtos de higiene produzidos pela Casa de Banho em Piracicaba - SP. O programa era a realização de um sonho dos sócios: combinar uma atuação que gerasse resultados 
CASA DE BANHO E O DESAFIO DA RESPONSABILIDADE SOCIAL EM MICRO E PEQUENAS EMPRESAS

Fernando do Amaral Nogueira, Cristina de Miranda Costa

$\overline{\text { financeiros e desenvolvimento social. No entanto, as fracas vendas do ano de } 2013 \text { punham em risco }}$ esse projeto.

\section{Da oficina mecânica à empresa, passando pelo cartório}

Em 2000, Patrícia e Fernando conheceram-se em uma oficina mecânica em Piracicaba SP, quando estavam os dois com seus carros quebrados. Ele, advogado, então com 28 anos, morava a $600 \mathrm{~km}$ dali e intencionava retornar à sua cidade após um final de semana de visita ao irmão, e tinha pressa. Ela, administradora de empresas, então com 30 anos, vivia na cidade, que era sua terra natal, e trabalhava em uma planta de produção de cosméticos pertencente a um grande grupo multinacional do setor químico.

Desde que se conheceram, ambos desejavam trabalhar de modo socialmente responsável, atuando sob valores compatíveis com uma sociedade solidária e impactando positivamente a vida das pessoas com quem se envolvessem. Perceberam que, desde sempre, queriam abrir um negócio que fosse capaz de garantir um sustento confortável e ser uma semente de mudança social, em especial no trabalho com jovens - e agradava Patrícia a ideia de que fosse algo relacionado com a noção de transformação, de beleza e conforto, com o provocar de sensações agradáveis.

Um ano depois, já casados e vivendo em Piracicaba, ela e Fernando juntaram-se a outros quatro sócios para, finalmente, darem início à Casa de Banho. A empresa inicialmente atuaria com representação de indústrias de cosméticos, somente até que pudesse ser levantado capital suficiente para a implementação física de uma loja multimarcas.

Essa etapa foi alcançada no segundo semestre de 2004, com a inauguração de um espaço físico de $130 \mathrm{~m}^{2}$, em que se vendiam diretamente ao consumidor cosméticos e artigos de toucador de mais de uma dezena de marcas nacionais e importadas de renome.

Os retornos financeiros dos primeiros seis meses de atividade mostraram-se positivos, mas o ano de 2005 trouxe desafios inesperados: houve grandes perdas, decorrentes de três assaltos à loja em menos de oito meses. A cada assalto, foi necessário recompor os estoques quase em sua totalidade.

Ainda que os planos iniciais tivessem sobrevivido às duas primeiras ocorrências, o terceiro assalto acabou levando à desistência dos demais sócios em prosseguir com o negócio, fazendo com que Patrícia e Fernando seguissem sós no comando da empresa. Na prática, isso os levou a refletir sobre o empreendimento e a eventualmente retroceder alguns estágios no planejamento antes traçado.

\section{Enfim sós: um novo caminho para a Casa de Banho}

Em 2006, após avaliação dos passos dados e reformulação do projeto, Patrícia e Fernando decidiram pela instituição de uma marca própria de cosméticos, voltada ao atacado (deixando de lado o varejo) e optando por não ter mais novos sócios para o empreendimento. O novo caminho abria a possibilidade para que tornassem realidade algum tipo de ação social associada ao seu negócio, desde há muito almejada.

Mas, antes disso, havia muito a ser feito. Ao longo dos anos seguintes, Patrícia e Fernando enfrentaram muitos desafios, como a criação da marca própria, seu registro no Instituto Nacional da Propriedade Industrial (INPI), o reduzido volume de recursos disponíveis, o redesenho 
do projeto, o desenvolvimento de produtos, a mudança para uma sede com $20 \%$ do tamanho do espaço anterior, a criação de uma rede de clientes e de representantes.

Atualmente, o desenvolvimento de fragrâncias e produtos é feito pela sócia Patrícia, junto a químicos e perfumistas contratados pontualmente para cada empreitada, enquanto Fernando se dedica às finanças e à contabilidade da empresa, e ambos determinam os rumos do negócio. A produção de águas de colônia, de splashes corporais desodorantes, de hidratantes corporais, para as mãos e para os pés e de aromatizadores de ambientes desenvolvidos e comercializados pela empresa é realizada de maneira terceirizada por indústria parceira. Representantes comerciais autônomos fomentam a rede de clientes em todo o Brasil, e os poucos funcionários fixos da empresa são contratados seguindo a Consolidação das Leis do Trabalho (CLT).

A proposta de valor e diferenciação da Casa de Banho reside na capacidade de personalização dos seus produtos de acordo com as demandas dos clientes atendidos - butiques, salões de beleza, joalherias - que associam sua imagem a fragrâncias desenvolvidas por Patrícia, seja para comercialização, seja para composição de brindes de luxo a consumidores finais (há alguns exemplos no Anexo 1). Assim, a Casa de Banho proporciona o envase e a rotulagem dos produtos em edições especiais levando o nome das marcas desses clientes. Ainda que os produtos permaneçam devidamente registrados sob a marca da Casa de Banho na Agência Nacional de Vigilância Sanitária (Anvisa), o registro é sempre realizado de modo que se permita a rotulagem das edições especiais para os clientes determinados, mantendo-se ali as informações obrigatórias, para cumprir as exigências legais.

Os sete anos transcorridos desde a criação da marca própria seguiram marcados por dificuldades típicas de um começo de negócio, relacionadas a margem de lucro, fluxo de caixa e sazonalidade na procura dos produtos pelos clientes (com picos em datas comemorativas como o Dia Internacional da Mulher, o Dia das Mães, o Dia dos Namorados e o Natal).

\section{Expansão: entram em jogo as aprendizes}

Em 2011, após ter sido admitida no Programa 10 Mil Mulheres ${ }^{1}$, Patrícia decidiu sofisticar ainda mais seus produtos, candidatando-os ao mercado de alto luxo, com a substituição das embalagens até então utilizadas, feitas de PET, por embalagens de vidro. Ainda que isso elevasse em $1.000 \%$ o custo da embalagem bruta, antes mesmo da personalização, possibilitaria a expansão das suas atividades para outro nicho.

A pronta aceitação dos produtos no novo nicho de mercado almejado trouxe a necessidade de expansão da linha de produção dos cosméticos em embalagens personalizadas - e também do local para instalação da equipe que viria tratar disso, o que motivou a mudança da empresa para um antigo casarão.

Foi assim que a Casa de Banho buscou, para além dos então quatro funcionários da empresa (os dois sócios inclusos) e da rede de representantes comerciais, a contratação de oito

\footnotetext{
${ }^{1}$ Lançado em 2008 pelo banco Goldman Sachs, o programa 10.000 Mulheres é uma iniciativa filantrópica global que dá educação em administração e gestão de negócios a mulheres de todo o mundo e busca melhorar a qualidade da educação empresarial nos países em desenvolvimento. No Brasil, o programa é desenvolvido em parceria com a FGV-EAESP e o IE Business School. Para mais informações: http://www.10000mulheres.com.br/
} 
estudantes de ensino médio, como aprendizes, por intermédio do Centro de Integração EscolaEmpresa $(\mathrm{CIEE})^{2}$.

Durante o processo de seleção, que se iniciou em fevereiro de 2012 e culminou com a contratação, em abril, de oito adolescentes com idades entre 16 e 18 anos, alunas do ensino médio, os sócios Patrícia e Fernando identificaram nas candidatas às vagas - todas mulheres - um perfil muito parecido, de situação de risco social. Isso se mostrava não somente por enfrentarem os desafios típicos da adolescência, mas sobretudo pela presença, naquelas garotas, da falta de referências positivas, de grande vulnerabilidade emocional diante da ausência de figuras de autoridade ou de ambientes familiares precários, da falta de projeto de vida e de grandes dificuldades financeiras. Eles viram, ali, a chance de desenvolverem a ação social desde há muito desejada e de maneira integrada, desde o seu núcleo ao desenvolvimento do negócio.

\section{Como funciona o programa}

As adolescentes são contratadas como aprendizes para atuar na linha de produção, em contratos sem duração mínima e que não podem exceder dois anos, para jornadas desenvolvidas no período complementar ao da escola e mediante remuneração de $\mathrm{R} \$ 500,00$ mensais, depositada diretamente pela Casa de Banho na conta-corrente própria de cada uma (a primeira conta bancária de todas elas). Ao CIEE, a empresa transfere o montante referente ao seguro de vida de cada uma, no valor individual de $\mathrm{R} \$ 68,00$ por mês, além de uma taxa fixa de manutenção de cadastro de $\mathrm{R} \$ 90,00$ mensais. Adicionalmente, ainda que não seja exigência legal, fornecem em dinheiro os valores correspondentes ao transporte necessário para seu deslocamento ao trabalho. Muitas optam por ir a pé à empresa para economizar essa quantia.

$\mathrm{Na}$ linha de produção, as aprendizes transferem o produto aos frascos; rotulam-nos de acordo com o pedido do cliente; adornam cuidadosamente cada um (com tules, tecidos, laços, fitas, contas e pedrarias); verificam a qualidade de acordo com o modelo-padrão de embalagem para aquele item; embalam cada qual individualmente em plástico; encaixotam as embalagens; identificam as caixas; e encaminham-nas à última sala de depósito do produto final para transporte e entrega aos clientes.

Como se trata de um trabalho que exige cuidado e delicadeza, Patrícia aproveita para orientar as aprendizes sobre a importância de atitudes básicas referentes a higiene e cuidados pessoais. Patrícia acredita que os produtos, sempre elogiados pelos clientes por conta do capricho com que são adornadas suas delicadas embalagens, não seriam tão bonitos se fossem produzidos de outra forma, em um contexto menos pessoal. Ela e Fernando estão convencidos do efeito transformador que a atividade de lidar com cuidado e com beleza provoca na vida dessas jovens, tanto quanto de que isso se reflete na qualidade do produto final.

O cuidado na relação com as aprendizes dá-se também de outras formas. Ainda que costumeiramente elas levem seu almoço, ou cheguem alimentadas quando vêm diretamente da escola, contam com uma dispensa e uma geladeira cheias. Patrícia seleciona vários tipos de alimentos, os quais podem ser consumidos livremente pelas garotas: não só sucos, verduras, legumes e frutas, como também biscoitos, bolos, doces e lanches. Esses mantimentos custam uma média mensal de $\mathrm{R} \$ 100,00$ por aprendiz.

\footnotetext{
${ }^{2}$ O CIEE é uma instituição que mantém cadastro de estudantes de ensino médio, técnico e superior dispostos a integrar o mundo do trabalho como aprendizes ou estagiários, e de empresas e outras organizações dispostas a contratá-los, e faz pontes entre esses atores.
} 
Entre outros benefícios, podemos citar:

- existe espaço e horário para que as adolescentes estudem e façam a lição de casa administrada pela escola, com escrivaninhas e computadores para uso exclusivo do grupo;

- existem momentos para discussão dos assuntos considerados mais importantes (para o bem e para o mal) em suas vidas. São chamados de rodas de conversa e realizados coletivamente entre as jovens e Patrícia;

- existem os momentos de educação em finanças pessoais, direitos e deveres da cidadania proporcionados às garotas por Fernando;

- existem os momentos de verificação, por Patrícia, da frequência e desempenho escolar das jovens (chegando ela até a comparecer em reuniões destinadas a pais e mestres em várias ocasiões, ao saber que mais ninguém acompanhava isso na vida das garotas);

- e existem, por fim, os momentos de profunda concentração na finalização das embalagens.

Uma frase repetidamente proferida por Patrícia e Fernando (e que é ostentada em alguns dos muitos cartazes motivacionais espalhados pelos cômodos do casarão que abriga a empresa) é: "Nenhuma empresa é maior que as pessoas que a constituem". As paredes do casarão trazem também outras mensagens, entre lembretes de segurança, cuidado, respeito e autorrespeito, identificação de cada item armazenado em cada canto, além da listagem das palavras-chave que descrevem filosofias de trabalho: organização, limpeza, higiene, disciplina e confiabilidade, entre outros valores.

A implementação dessas iniciativas sociais também foi marcada por algumas dificuldades. A primeira é a informalidade e falta de planejamento e avaliação das atividades. Além disso, estão atuando de maneira isolada, sem apoio do CIEE ou de qualquer outra instituição que pudesse orientar e sugerir melhores práticas em programas de responsabilidade social, ou fornecer informações sobre como lidar com os desafios e as necessidades das jovens do programa. Estão tentando melhorar o apoio às aprendizes com a ajuda de psicólogas e pedagogas voluntárias, indicadas por amigos.

Patrícia lembra-se de dois exemplos que mostram a importância de valorizar o desenvolvimento das jovens. Veio dessas adolescentes a sugestão de que cada frasco fosse embalado separadamente em plástico, e devidamente selado, antes de encaixotado. Assim, eventuais quebras de vidro não fariam o produto vazar para os demais itens da caixa, evitando a destruição da decoração de todo o lote. Outra sugestão foi a ideia de serem usados jornais e revistas desprezados, picados em picotadora, para preenchimento dos espaços vazios das caixas, para efeito de amortecimento de impacto, em lugar do isopor (mais poluente e difícil de reciclar).

Patrícia e Fernando ainda não têm uma política clara de comunicação sobre esses valores e práticas para sua cadeia de fornecedores (gráfica, indústria química etc.), parceiros (representantes comerciais) e clientes (varejistas) - alguns conhecem as práticas da empresa, outros não. Patrícia questiona se a revelação de que aqueles produtos finos resultam do trabalho de adolescentes em situação de risco social agregaria valor a seu produto aos olhos de todos os seus clientes ou se haveria aqueles que passariam a rejeitar sua produção:

O ideal seria que os clientes e parceiros sentissem vontade de fazer o mesmo por essas jovens, mas, para muita gente, elas inspiram muito medo. Mas, enfim, se houver cliente que se incomode com isso, talvez ele não deva mesmo vender os nossos produtos, não é? 


\section{Ano novo, dificuldades novas...}

Olhando para o casarão alugado onde está a Casa de Banho, Patrícia faz muitos planos: quer comprar o imóvel, reformá-lo e expandi-lo, cultivar ali uma horta... Existem até planos de expansão de sua atuação empreendedora, criando outras empresas que sigam a mesma filosofia de gestão de pessoas da Casa de Banho: uma lanchonete em uma área da cidade recentemente ocupada por uma instituição de ensino superior, e em que há carência de estabelecimentos do gênero, ou, ainda, uma agência de viagens voltada ao atendimento do público de Gays, Lésbicas, Bissexuais, Travestis e Transexuais (GLBTT), o que seria inédito na cidade.

Mas o ano de 2013 tem sido difícil para a empresa. Desde as encomendas feitas no início do segundo semestre de 2012 e das entregas correspondentes feitas até o Natal, não houve mais boas vendas. Os varejistas clientes da Casa de Banho queixam-se de quedas de cerca de $40 \%$ nas vendas nesse ano, em relação ao ano anterior. Assim, as encomendas à empresa também se reduziram drasticamente, e muitas puderam ser atendidas com estoques já montados.

Patrícia e Fernando demonstram alívio por, ao menos, estarem sendo capazes de passar por essa estagnação do mercado sem contraírem dívidas - o que poderia resultar no encerramento das atividades da empresa. Mas, ainda assim, viram-se, em fevereiro de 2013, na situação de terem que dispensar as aprendizes.

Foi mantida somente uma delas, que demonstrara também grande talento para confecção de imagens e vídeos para a propaganda dos produtos e na manutenção e monitoramento dos perfis da empresa nas redes sociais. No entanto, recentemente ela se desligou da empresa por determinação médica, já que o contrato de aprendiz não prevê afastamento pela Previdência Social. Ela continua contando com a ajuda de seus antigos chefes, que esperam a oportunidade de recontratá-la futuramente.

Os sócios gostariam de abrir um novo processo seletivo em agosto, mais uma vez por intermédio do CIEE, e esperam que a Casa de Banho possa voltar a contratar aprendizes até setembro - ainda não sabem quantas, o que vai ser determinado pelo volume das encomendas para o Natal.

Patrícia já faz planos para essa possível nova turma: além de replicar o que funcionou com a primeira, pensa em trazer novidades, como um blog em que ela e as aprendizes escrevam sobre a experiência, para que esses relatos inspirem outras microempresas.

Mas, antes disso, é preciso saber se a Casa de Banho comportará mesmo a continuidade do programa. Ao comentar o momento atual com amigos e familiares, há quem diga claramente para ela "deixar pra lá essa coisa com as meninas" e simplesmente contratar alguns funcionários CLT, que provavelmente dariam menos trabalho e conseguiriam ser mais produtivos - quem sabe até mais baratos. Ou, quem sabe, uma estrutura mínima com apoio de uma terceirizada. Essas alternativas ainda liberariam tempo da Patrícia para pensar em novas estratégias de venda, busca de novos mercados, reconquista de clientes... Talvez fosse o caso de voltar aos programas sociais só quando a empresa estivesse maior, mais sólida. 
CASA DE BANHO E O DESAFIO DA RESPONSABILIDADE SOCIAL EM MICRO E PEQUENAS EMPRESAS Fernando do Amaral Nogueira, Cristina de Miranda Costa

\section{Anexo 1}

\section{Exemplo de duas linhas de produtos próprias da Casa de Banho}

\section{LINHA SENSUAL}

As mulheres sofisticadas, sedutoras e, principalmente, jovens de espírito certamente encontrarão sua identidade nessa fragrância floral-frutal composta de notas sensuais como groselha vermelha, rosa canina, laranja, frésia, canela, pêssego e fundo marcado pelo cedro.

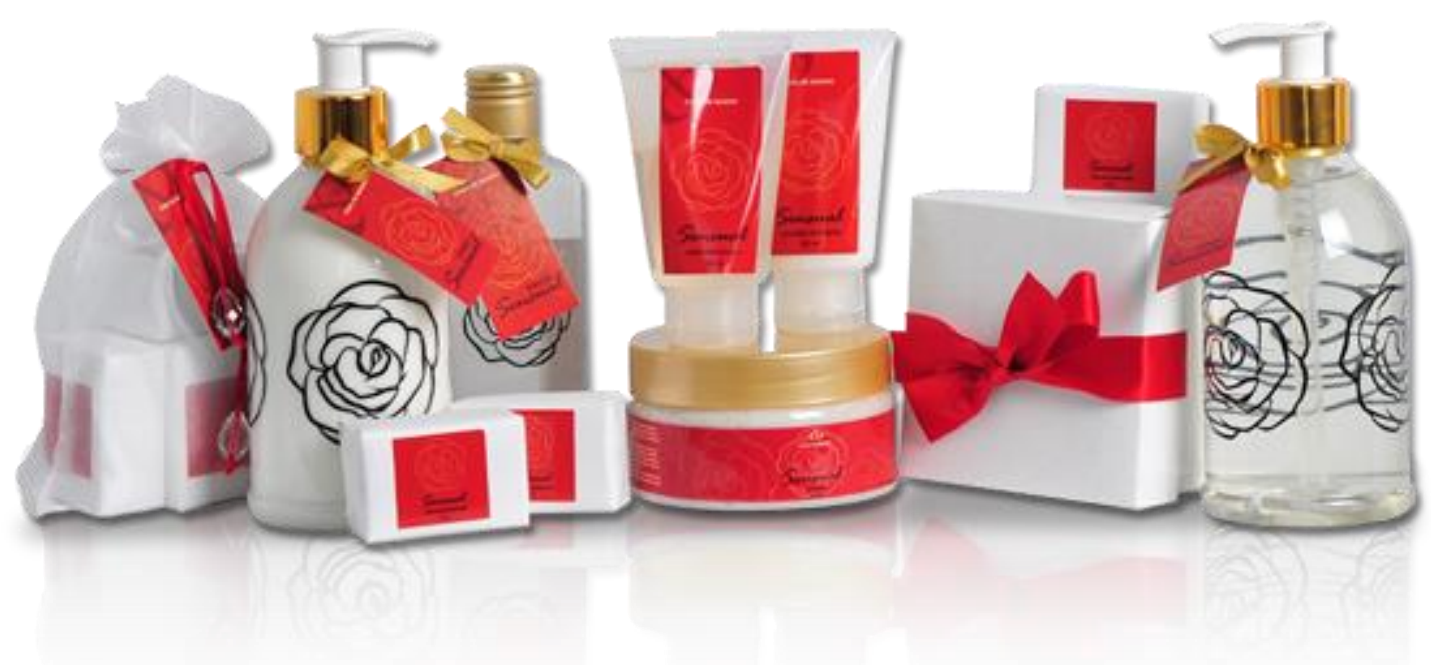

\section{LINHA JUVENILE}

Jovialidade e o frescor pueril traduzem esse frutal refrescante para meninas-mulheres, que preferem seduzir por meio de um charme inocente. Para tal êxito, combinamos notas de bergamota, tangerina, amora, groselha preta, maracujá, almíscar e âmbar.

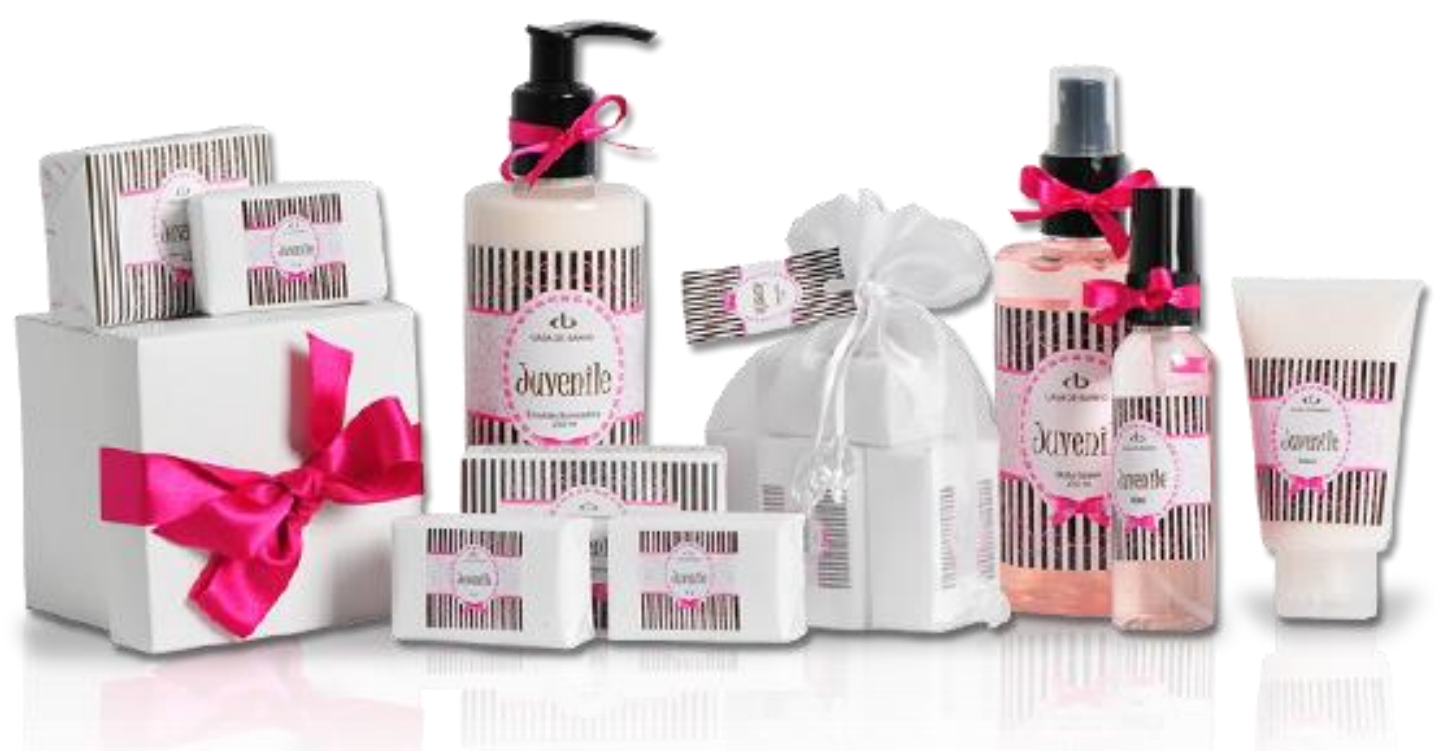

Fonte: http://www.casadebanho.com.br 